\title{
Coffee intake and risk of incident diabetes in Puerto Rican men: results from the Puerto Rico Heart Health Program
}

\author{
BJ Fuhrman ${ }^{1}$, E Smit $^{2}$, CJ Crespo ${ }^{2, *}$ and MR Garcia-Palmieri ${ }^{3}$ \\ ${ }^{1}$ Health Behaviors, Cancer Prevention and Population Sciences, Roswell Park Cancer Institute, Buffalo, NY, USA: \\ ${ }^{2}$ School of Community Health, Portland State University, 506 Mill Street, 450-A Urban Center, Portland, \\ OR 97201, USA: ${ }^{3}$ School of Medicine, University of Puerto Rico, San Juan, Puerto Rico
}

Submitted 31 July 2007: Accepted 19 May 2008: First published online 2 September 2008

\begin{abstract}
Objective: To study prospectively the association of coffee intake with incident diabetes in the Puerto Rico Heart Health Program cohort, comprising 9824 middle-aged men (aged 35-79 years).

Methods: Of 9824 men, 3869 did not provide a fasting blood sample at baseline, 1095 had prevalent diabetes and 131 were not given fasting glucose tests at any subsequent study visit. Thus, the present analysis includes 4685 participants. Diabetes was ascertained at baseline and at two study visits between 1968 and 1975 using fasting glucose tests and self-reports of physician-diagnosed diabetes or use of insulin or hypoglycaemic medication. Logistic regression analysis was used to assess the association of coffee intake with risk of incident diabetes while adjusting for covariates (age, BMI, physical activity, smoking, education, alcohol intake, family history of diabetes, intakes of milk and sugar).

Results: Five hundred and nineteen participants met the criteria for incident diabetes. Compared with those reporting intake of 1-2 servings of coffee/d, coffee abstainers were at reduced risk $(\mathrm{OR}=0 \cdot 64 ; 95 \% \mathrm{CI} 0 \cdot 43,0 \cdot 94)$. Among coffee drinkers, there was a significant trend of decreasing risk by intake $(P=0 \cdot 02)$; intake of $\geq 4$ servings/d was associated with an odds ratio of 0.75 (95\% CI $0.58,0.97$ ). Conclusions: Study findings support a protective effect of coffee intake on diabetes risk, while also suggesting that abstainers may be at reduced risk.
\end{abstract}

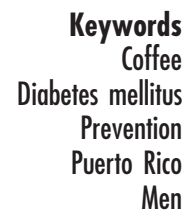

In the USA and worldwide, rates of type 2 diabetes mellitus are expected to increase substantially in response to demographic shifts and the increasing prevalence of important risk factors for this disease, in particular obesity and sedentary lifestyle ${ }^{(1)}$. Diabetes is associated with severe morbidity and premature mortality, and so this epidemic poses a large and increasing burden on global public health. An understanding of dietary factors that can reduce diabetes risk may provide the basis for preventive strategies.

It is recognized that in the USA diabetes disproportionately affects Hispanics, particularly MexicanAmericans and Puerto Ricans. Data from the Hispanic Health and Nutrition Examination Surveys have found that the rates of diagnosed diabetes among persons 45-74 years of age are higher for persons of Mexican and Puerto Rican origin compared with non-Hispanic whites and blacks ${ }^{(2)}$. According to the Behavioral Risk Factor and Surveillance System, in 2005 the highest prevalence of self-reported physician-diagnosed diabetes in the USA was in the Commonwealth of Puerto Rico ${ }^{(3)}$. Moreover, age-adjusted mortality from diabetes in the Commonwealth of Puerto Rico in 2000 was $71 \cdot 8$ per 100000 population, while the state with the next highest ageadjusted mortality rate was Louisiana (41.9 per 100000$)$ and the overall rate for the USA was $25 \cdot 2$ per $100000^{(4)}$. Thus, identifying behaviours related to incident diabetes and excess burden of diabetes among Puerto Ricans is of great public health significance.

In 2002 van Dam and Feskens published their novel finding of an inverse association between coffee intake and risk of type 2 diabetes among members of a cohort of Dutch men and women ${ }^{(5)}$. Many subsequent findings from prospective studies conducted in Europe, the USA and Japan have also supported a protective effect of coffee drinking on risk of diabetes ${ }^{(5-15)}$. Two prospective studies, one conducted in Finland and the other among the Pima Indians, did not find this association ${ }^{(16,17)}$.

To date, no studies on the association of coffee with diabetes risk have been conducted in Hispanic populations. Available information suggests that Puerto Ricans differ from other Americans in methods of coffee preparation $^{(18)}$ and serving size ${ }^{(19)}$; in general, coffee is consumed in a highly concentrated form and in small portions. Little information is available regarding the relative frequency of 
coffee intake in this ethnic group. It is not known whether high diabetes rates observed in Puerto Rico and among Puerto Ricans living in the eastern USA can be attributed to differences in coffee intake among Puerto Ricans compared with non-Hispanic Americans.

Considering the high burden of diabetes among this under-studied Hispanic subgroup, in the present study we prospectively examined the association of coffee drinking and incident diabetes in a cohort of Puerto Rican men.

\section{Methods}

The Puerto Rico Heart Health Program (PRHHP) is a prospective cohort study designed to assess morbidity and mortality from CHD among Puerto Rican men. This cohort represents a population-based sample of middleaged men drawn from three urban areas and four rural areas in the north-eastern part of Puerto Rico. Invitations to participate in the study were sent to 12167 men who had been enumerated in house-to-house surveys conducted in the region by personnel of the US Decennial Census, which had occurred in 1960. Of those invited, 9824 (81\%) enrolled and completed baseline examinations (1965-1968). While the original sampling design for the cohort included only men aged 45-64 years, some additional men aged $35-44$ years $(n 349)$ and $65-79$ years ( $n$ 682) were included in the study to promote good community relations. After baseline, there were three subsequent follow-up examinations, which took place during the years 1968-71, 1971-5 and 1974-7. Study participants were followed for CHD mortality events over a 12-year period; however diabetes was assessed only at baseline and during the first and second follow-up examinations.

For the present analysis, we excluded participants who failed to fast ( $n$ 3869) or to provide a blood sample at the baseline examination ( $n$ 44), participants who were ascertained as having diabetes at baseline ( $n$ 1095) and participants who were not given a fasting glucose test on at least one occasion after baseline ( $n$ 131). Thus, our study includes 4685 participants determined to be without diabetes at baseline and who provided fasting samples for glucose testing at one or more subsequent study visits, occurring between 1968 and 1975. At each study visit, diabetes was assessed by asking participants whether they had been diagnosed with the disease by their physician and whether they used diabetes medications; in addition, fasting blood samples were drawn for glucose testing. For the purposes of the study, fasting blood glucose $>126 \mathrm{mg} / \mathrm{dl}$ was considered to indicate diabetes as per criteria delineated by the $\mathrm{WHO}^{(20)}$.

During the baseline examination, all men completed an extensive self-report of demographic characteristics, personal and family health history and health habits, including education, occupation, income, history of smoking and place of residence. Dietary intake was assessed using a $24 \mathrm{~h}$ dietary recall, with food models and standard-sized utensils used to obtain quantitative assessments from participants. Intakes of energy and macronutrients were calculated using the US Department of Agriculture Handbook $\# 8$ food composition tables ${ }^{(21)}$ or other more direct sources of nutrient analysis for foods specific to Puerto Rico. It is customary in Puerto Rico to drink approximately $30 \mathrm{ml}$ of highly concentrated coffee with $118 \mathrm{ml}$ of milk. Estimates of milk and sugar intakes were calculated from $24 \mathrm{~h}$ recall data and include amounts of these foods consumed with coffee and separately. Physical activity was assessed using the Framingham Physical Activity Index, which is a score representing participants' daily energy expenditure based upon selfreported usual daily activities and their duration ${ }^{(22)}$.

Statistical analyses were done using the Statistical Package for the Social Sciences statistical software package version $13 \cdot 0$ (SPSS Inc., Chicago, IL, USA). Logistic regression models were used to assess associations of the factors under study with risk of incident diabetes. Coffee intake was categorized into none (0), 1-2, 3 and $\geq 4$ servings/d. For tests of trend, subjects were assigned the median coffee intake for the category to which they belonged. In our analysis the following covariates were assessed at baseline: age, level of education, residence (rural, urban), family history of diabetes (no, yes), calculated BMI (continuous), index of physical activity (categorical), cigarette-smoking status (never, current, and former) and alcohol intake as reported in a $24 \mathrm{~h}$ recall (none, any) were all considered as potential confounders. For multivariate modelling, we considered all variables with statistically significant or near-significant $(P<0 \cdot 10)$ crude associations with both exposure and disease measures as potential confounders. Parsimonious models included only those variables selected using a forward-conditional algorithm. Saturated models included all potential confounding variables. Intakes of milk and sugar were also included in models as potential confounders.

The research was approved by the Institutional Review Board of the University at Buffalo. Study participants gave informed consent at the time of enrolment.

\section{Results}

We examined the association of coffee consumption with incident diabetes among 4685 PRHHP study participants without diabetes at baseline. A total of 519 (11\%) participants met criteria for incident diabetes over a median follow-up period of $2 \cdot 6$ years, for an incidence rate of 42.6 per 1000 person-years. Selected baseline characteristics of the study population and the incidence of diabetes are shown in Table 1. In our sample, median age at the time of diabetes ascertainment was 56 years. Rather than increasing with age at baseline as expected, diabetes 
Table 1 Rate of incident diabetes (\%) in strata of selected covariates among men in the Puerto Rico Heart Health Program cohort

\begin{tabular}{|c|c|c|c|c|c|}
\hline & $n$ & $\%$ & No. of incident cases & Crude rate $(\%)$ & $P$ value* \\
\hline Age at baseline (years) & & & & & 0.020 \\
\hline $37-44$ & 1264 & $27 \cdot 0$ & 147 & $11 \cdot 6$ & \\
\hline $45-54$ & 1297 & $27 \cdot 7$ & 145 & $11 \cdot 2$ & \\
\hline $55-64$ & 1025 & $21 \cdot 9$ & 118 & $11 \cdot 5$ & \\
\hline $65-77$ & 1099 & $23 \cdot 5$ & 109 & $9 \cdot 9$ & \\
\hline Level of education & & & & & 0.013 \\
\hline No formal education & 456 & $9 \cdot 7$ & 30 & $6 \cdot 6$ & \\
\hline Grades 1 to 8 & 2953 & $63 \cdot 0$ & 337 & $11 \cdot 4$ & \\
\hline High school and/or college & 1276 & $27 \cdot 2$ & 152 & $11 \cdot 9$ & \\
\hline Residence & & & & & $<0.001$ \\
\hline Rural & 1534 & $32 \cdot 7$ & 129 & $8 \cdot 4$ & \\
\hline Urban & 3151 & $67 \cdot 3$ & 390 & $12 \cdot 4$ & \\
\hline BMI $\left(\mathrm{kg} / \mathrm{m}^{2}\right)$ & & & & & $<0.001$ \\
\hline Underweight (BMI < 18.5) & 130 & $2 \cdot 8$ & 9 & $6 \cdot 9$ & \\
\hline Normal $(\mathrm{BMI}=18 \cdot 5-24.9)$ & 2227 & $47 \cdot 5$ & 151 & $6 \cdot 8$ & \\
\hline Overweight $(\mathrm{BMI}=25 \cdot 0-29 \cdot 9)$ & 1755 & $37 \cdot 5$ & 221 & $12 \cdot 6$ & \\
\hline Obese $(\mathrm{BMI} \geq 30 \cdot 0)$ & 573 & $12 \cdot 2$ & 138 & $24 \cdot 1$ & \\
\hline Physical activity index & & & & & 0.028 \\
\hline First quartile (sedentary) & 1155 & $24 \cdot 7$ & 134 & $11 \cdot 6$ & \\
\hline Second quartile & 1254 & $26 \cdot 8$ & 153 & $12 \cdot 2$ & \\
\hline Third quartile & 1089 & $23 \cdot 2$ & 127 & $11 \cdot 7$ & \\
\hline Fourth quartile (active) & 1187 & $25 \cdot 3$ & 105 & $8 \cdot 8$ & \\
\hline Smoking status & & & & & 0.015 \\
\hline Never smoked & 1624 & $34 \cdot 7$ & 191 & $11 \cdot 8$ & \\
\hline Current smoker & 1964 & $41 \cdot 9$ & 188 & $9 \cdot 6$ & \\
\hline Former smoker & 1097 & $23 \cdot 4$ & 140 & $12 \cdot 8$ & \\
\hline Family history of diabetes & & & & & 0.001 \\
\hline No & 3966 & $84 \cdot 7$ & 402 & $10 \cdot 1$ & \\
\hline Yes & 719 & $15 \cdot 3$ & 117 & $16 \cdot 3$ & \\
\hline Alcohol intake (g/week) & & & & & 0.01 \\
\hline None & 3670 & $78 \cdot 3$ & 379 & $10 \cdot 3$ & \\
\hline$>1($ median 31, SE 1.4$)$ & 1014 & $21 \cdot 6$ & 140 & $13 \cdot 8$ & \\
\hline Sugar intake $(g / d)$ & & & & & $<0.001$ \\
\hline$\leq 24$ & 1068 & $22 \cdot 8$ & 154 & $14 \cdot 4$ & \\
\hline $25-45$ & 1179 & $25 \cdot 2$ & 144 & $12 \cdot 2$ & \\
\hline $46-70$ & 1185 & $25 \cdot 3$ & 98 & $8 \cdot 3$ & \\
\hline$\geq 71$ & 1252 & $26 \cdot 7$ & 123 & $9 \cdot 8$ & \\
\hline Milk intake (servings/d) $\dagger$ & & & & & 0.01 \\
\hline$\leq 2$ & 1589 & 33.9 & 194 & $12 \cdot 2$ & \\
\hline $3-4$ & 1331 & $28 \cdot 4$ & 158 & $11 \cdot 9$ & \\
\hline $5-6$ & 961 & $20 \cdot 5$ & 89 & $9 \cdot 3$ & \\
\hline$\geq 7$ & 804 & $17 \cdot 2$ & 78 & $9 \cdot 7$ & \\
\hline Coffee intake (servings/d)† & & & & & 0.002 \\
\hline 0 & 352 & $7 \cdot 5$ & 34 & $9 \cdot 7$ & \\
\hline $1-2$ & 1919 & $41 \cdot 0$ & 262 & $13 \cdot 7$ & \\
\hline 3 & 1079 & $23 \cdot 0$ & 108 & $10 \cdot 0$ & \\
\hline$\geq 4$ & 1335 & 28.5 & 115 & $8 \cdot 6$ & \\
\hline
\end{tabular}

${ }^{*}$ For nominal variables, $P$ represents the difference in distribution among categories. For quantitative dependent variables, $P$ is for linear trend in diabetes risk across categories.

tEach serving of coffee is approximately $30 \mathrm{ml}$, while each serving of milk is $118 \mathrm{ml}$.

incidence remained level across middle age (37-64 years) and then declined at more advanced ages. This pattern results from exclusions of prevalent diabetes cases from the study sample. Incidence of adult-onset diabetes was higher among those who were more educated, those who lived in urban areas, who were overweight and especially obese, less physically active and who had a family history of diabetes. Incidence of diabetes was lower among those who were current smokers at baseline. Milk intake, sugar intake and coffee intake was each inversely associated with diabetes, while alcohol intake was directly associated with diabetes. Median self-reported coffee intake in the sample of Puerto Rican men was 3 servings daily.
As seen in Table 2, higher coffee intake was significantly associated with lower educational attainment, rural residence, normal or low BMI, higher levels of physical activity, current smoking, no regular alcohol intake and no family history of diabetes.

Logistic regression models to describe the association of coffee drinking with incident diabetes are presented in Table 3. Using 1-2 servings coffee/d as the reference category, there was an inverse association for coffee abstainers (OR $=0.64 ; 95 \% \mathrm{CI} 0.43,0.94)$ as well as for those drinking 3 servings $/ \mathrm{d}(\mathrm{OR}=0.79 ; 95 \%$ CI 0.69 , $1.00)$ and $\geq 4$ servings/d (OR $=0.75 ; 95 \%$ CI $0.58,0.97)$ after adjusting for covariates. Results were consistent in 
Table 2 Participant characteristics by self-reported baseline coffee intake among men in the Puerto Rico Heart Health Program cohort

\begin{tabular}{|c|c|c|c|c|c|c|c|c|c|}
\hline & \multicolumn{8}{|c|}{ Coffee intake (servings/d) ${ }^{\star}$} & \multirow[b]{3}{*}{$P$ valuet } \\
\hline & \multicolumn{2}{|c|}{$\begin{array}{c}0 \\
(n 352)\end{array}$} & \multicolumn{2}{|c|}{$\begin{array}{c}1-2 \\
(n 1919)\end{array}$} & \multicolumn{2}{|c|}{$\begin{array}{c}3 \\
(n 1079)\end{array}$} & \multicolumn{2}{|c|}{$\begin{array}{c}\geq 4 \\
(n 1335)\end{array}$} & \\
\hline & Mean & SE & Mean & SE & Mean & SE & Mean & SE & \\
\hline Age at baseline (years) & $53 \cdot 6$ & $0 \cdot 3$ & $54 \cdot 2$ & $0 \cdot 1$ & $54 \cdot 5$ & $0 \cdot 2$ & $54 \cdot 3$ & $0 \cdot 2$ & 0.152 \\
\hline \multirow[t]{2}{*}{ BMI $\left(\mathrm{kg} / \mathrm{m}^{2}\right)$} & $25 \cdot 6$ & $0 \cdot 2$ & $25 \cdot 6$ & $0 \cdot 1$ & $25 \cdot 1$ & $0 \cdot 1$ & $24 \cdot 5$ & $0 \cdot 1$ & $<0.001$ \\
\hline & $n$ & $\%$ & $n$ & $\%$ & $n$ & $\%$ & $n$ & $\%$ & \\
\hline Level of education & & & & & & & & & $<0.001$ \\
\hline No formal education & 18 & $5 \cdot 1$ & 173 & $9 \cdot 0$ & 122 & $11 \cdot 3$ & 143 & $10 \cdot 7$ & \\
\hline Grades 1 to 8 & 229 & $65 \cdot 1$ & 1169 & $60 \cdot 9$ & 686 & $63 \cdot 6$ & 869 & $65 \cdot 1$ & \\
\hline High school and/or college & 105 & $29 \cdot 8$ & 577 & $30 \cdot 1$ & 271 & $25 \cdot 1$ & 323 & $24 \cdot 2$ & \\
\hline Urban residence & 268 & $76 \cdot 1$ & 1408 & $73 \cdot 4$ & 707 & $65 \cdot 5$ & 768 & $57 \cdot 5$ & $0 \cdot 149$ \\
\hline Physical activity index & & & & & & & & & $<0.001$ \\
\hline Quartile 1 (sedentary) & 106 & $30 \cdot 1$ & 514 & $26 \cdot 8$ & 258 & $23 \cdot 9$ & 277 & $20 \cdot 7$ & \\
\hline Quartile 2 & 111 & $31 \cdot 5$ & 554 & $28 \cdot 9$ & 287 & $26 \cdot 6$ & 302 & $22 \cdot 6$ & \\
\hline Quartile 3 & 62 & $17 \cdot 6$ & 466 & $24 \cdot 3$ & 234 & $21 \cdot 7$ & 327 & $24 \cdot 5$ & \\
\hline Quartile 4 (active) & 73 & $20 \cdot 7$ & 385 & $20 \cdot 1$ & 300 & $27 \cdot 8$ & 429 & $32 \cdot 1$ & \\
\hline Smoking status & & & & & & & & & 0.079 \\
\hline Never smoked & 140 & $39 \cdot 8$ & 770 & $40 \cdot 1$ & 351 & $32 \cdot 5$ & 363 & $27 \cdot 2$ & \\
\hline Current smoker & 108 & $30 \cdot 7$ & 723 & $37 \cdot 7$ & 474 & $43 \cdot 9$ & 659 & $49 \cdot 4$ & \\
\hline Former smoker & 104 & $29 \cdot 5$ & 426 & $22 \cdot 2$ & 254 & $23 \cdot 5$ & 313 & $23 \cdot 4$ & \\
\hline Family history of diabetes & 57 & $16 \cdot 2$ & 310 & $16 \cdot 2$ & 163 & $15 \cdot 1$ & 189 & $14 \cdot 2$ & 0.024 \\
\hline Alcohol intake (g/week) & & & & & & & & & $<0.001$ \\
\hline None & 276 & $78 \cdot 4$ & 1431 & $74 \cdot 6$ & 864 & $80 \cdot 1$ & 1099 & $82 \cdot 3$ & \\
\hline$>1$ (median 31, SE 1·4) & 76 & $21 \cdot 6$ & 488 & $25 \cdot 4$ & 214 & $19 \cdot 9$ & 236 & $17 \cdot 7$ & \\
\hline Sugar intake $(g / d)$ & & & & & & & & & $<0.001$ \\
\hline$\leq 24$ & 148 & $42 \cdot 0$ & 658 & $34 \cdot 3$ & 155 & $14 \cdot 4$ & 107 & $8 \cdot 0$ & \\
\hline $25-45$ & 67 & $19 \cdot 0$ & 541 & $28 \cdot 1$ & 281 & $26 \cdot 1$ & 291 & $21 \cdot 8$ & \\
\hline $46-70$ & 75 & $21 \cdot 3$ & 357 & $18 \cdot 6$ & 363 & $33 \cdot 7$ & 390 & $29 \cdot 2$ & \\
\hline$\leq 71$ & 62 & $17 \cdot 6$ & 364 & $19 \cdot 0$ & 279 & $25 \cdot 9$ & 547 & $41 \cdot 0$ & \\
\hline Milk intake (servings/d)* & & & & & & & & & $<0.001$ \\
\hline$\leq 2$ & 155 & $44 \cdot 0$ & 910 & $47 \cdot 4$ & 238 & $22 \cdot 1$ & 286 & $21 \cdot 4$ & \\
\hline $3-4$ & 73 & $20 \cdot 7$ & 466 & $24 \cdot 3$ & 400 & $37 \cdot 1$ & 392 & $29 \cdot 4$ & \\
\hline $5-6$ & 63 & $17 \cdot 9$ & 321 & $16 \cdot 7$ & 241 & $22 \cdot 3$ & 336 & $25 \cdot 2$ & \\
\hline$\geq 7$ & 61 & $17 \cdot 3$ & 222 & $11 \cdot 6$ & 200 & $18 \cdot 5$ & 321 & $24 \cdot 0$ & \\
\hline
\end{tabular}

*Each serving of coffee is approximately $30 \mathrm{ml}$, while each serving of milk is $118 \mathrm{ml}$.

$+P$ is for the linear trend across categories of coffee intake.

Table 3 Odds ratios for the association of coffee intake (quartiles) with incident diabetes among men in the Puerto Rico Heart Health Program

\begin{tabular}{|c|c|c|c|c|c|c|c|c|}
\hline & \multicolumn{8}{|c|}{ Self-reported coffee intake (servings/d)* } \\
\hline & \multicolumn{2}{|r|}{0} & \multicolumn{2}{|c|}{$1-2$} & \multicolumn{2}{|c|}{3} & \multicolumn{2}{|c|}{$\geq 4$} \\
\hline No. of new diabetes cases & \multicolumn{2}{|c|}{352} & \multicolumn{2}{|c|}{1919} & \multicolumn{2}{|c|}{1079} & \multicolumn{2}{|c|}{1335} \\
\hline Total no. of men & & 352 & & & & 079 & & 335 \\
\hline \multirow[t]{2}{*}{ Person-years of follow-up } & \multicolumn{2}{|c|}{953} & \multicolumn{2}{|c|}{5258} & \multicolumn{2}{|c|}{2958} & \multicolumn{2}{|c|}{3665} \\
\hline & OR & $95 \% \mathrm{Cl}$ & OR & $95 \% \mathrm{Cl}$ & OR & $95 \% \mathrm{Cl}$ & OR & $95 \% \mathrm{Cl}$ \\
\hline Multivariate model $1 \dagger$ & 0.66 & $0.45,0.97$ & $1 \cdot 00$ & referent & $0 \cdot 75$ & $0.59,0.96$ & 0.69 & $0.54,0.87$ \\
\hline Multivariate model $2 \ddagger$ & 0.64 & $0.43,0.94$ & $1 \cdot 00$ & referent & $0 \cdot 79$ & $0.69,1.00$ & $0 \cdot 75$ & $0.58,0.97$ \\
\hline
\end{tabular}

*Each serving of coffee represents approximately $30 \mathrm{ml}$.

tAdjusted for variables selected in a forward-conditional linear model: BMI, family history of diabetes and alcohol intake.

$\ddagger$ Adjusted for age, BMI, smoking status, family history of diabetes, education, alcohol intake, index of physical activity, milk and sugar intakes.

models using two sets of covariates: the first a parsimonious model using only those variables selected by a stepwise algorithm; and the second adjusting for other potential covariates identified in the literature as well as intakes of milk and sugar, which are often consumed with coffee and could potentially be associated with diabetes. When coffee abstainers were excluded, the trend across categories of intake was statistically significant $(P=0 \cdot 02)$ after adjustment for age, BMI, index of physical activity, smoking status, family history of diabetes, education, alcohol intake, milk and sugar intakes.

A number of additional analyses were conducted to explore the way that study limitations may have influenced study findings. 
Table 4 Adjusted* mean daily servings of coffeet by diabetes outcome among 4685 men in the Puerto Rico Heart Health Program

\begin{tabular}{|c|c|c|c|c|c|c|c|}
\hline & \multicolumn{2}{|c|}{ No diabetes } & \multicolumn{2}{|c|}{ Incident diabetes } & \multirow[b]{2}{*}{ Mean difference } & \multirow[b]{2}{*}{ SE } & \multirow[b]{2}{*}{$P$ value } \\
\hline & Mean & SE & Mean & SE & & & \\
\hline Among all participants & $2 \cdot 79$ & 0.05 & $2 \cdot 64$ & 0.09 & $0 \cdot 15$ & 0.08 & 0.07 \\
\hline Among all coffee drinkers & $2 \cdot 98$ & 0.04 & $2 \cdot 76$ & 0.08 & $0 \cdot 22$ & 0.08 & $<0.01$ \\
\hline
\end{tabular}

${ }^{*}$ Adjusted for age, BMI, physical activity index, smoking status, family history of diabetes, education, alcohol intake, milk and sugar. Covariates appearing in the model are evaluated at the following values: age $=54 \cdot 3$ years, $\mathrm{BMI}=25 \cdot 2 \mathrm{~kg} / \mathrm{m}^{2}$.

tEach serving of coffee represents approximately $30 \mathrm{ml}$.

With a single $24 \mathrm{~h}$ dietary recall, intra-individual variation may result in measurements that do not adequately represent an individual's usual intake. However, it is accepted that $24 \mathrm{~h}$ recalls provide reasonable group estimates $^{(23)}$. Thus we have also analysed our data from this perspective, as seen in Table 4, where covariate-adjusted group means for baseline coffee intake are compared between participants who developed incident diabetes during the course of the study and those who did not. Results are consistent with the findings of logistic regression analysis, as described above. When coffee abstainers were included, a near-significant difference in baseline coffee intake can be discerned $(P=0 \cdot 07)$, with lower adjusted mean servings of coffee reported by men who went on to have diabetes compared with those who remained healthy. When abstainers were excluded from the sample, a small but highly significant difference in coffee intake became apparent $(P<0 \cdot 01)$.

Results of one methodological study suggest that coffee intake can be measured reliably using dietary recalls ${ }^{(24)}$, while another suggests that an individual's coffee intake may vary by day of the week ${ }^{(25)}$. Because of the prospective study design, it is likely that any misclassification of coffee intake would be non-differential and thus would tend to bias results towards the null. Furthermore, when logistic models were run on a subset of participants excluding those with baseline visits occurring on Mondays (and so whose $24 \mathrm{~h}$ recalls reflect weekend rather than weekday habits), results were not meaningfully different from those presented in Table 3.

Another important limitation of the present research is the fact that 3869 potentially eligible participants failed to fast prior to providing blood specimens at baseline or at subsequent study visits. Participants who reported not fasting at the baseline visit were less likely to be overweight $(P<0 \cdot 001)$, had less education $(P<0 \cdot 001)$ and were more likely to be current smokers $(P<0 \cdot 001)$ than those who did fast. These participants were excluded from the study due to concerns that inclusion of subjects who were not assessed in a valid manner for diabetes at baseline could introduce biases into the study. However, when non-fasting participants were included in the study sample the same pattern of associations was seen, with both coffee abstainers and drinkers of 3 and $\geq 4$ servings of coffee daily having inverse associations with diabetes after adjustment for covariates.
A final potential limitation of the research is the relatively short follow-up time, with a median time of 2.6 years (range: 2-7 years) from baseline to the last diabetes assessment completed. When coffee intake was compared in incident diabetes cases ascertained at the first follow-up visit and those ascertained at the second follow-up visit, we found higher intake in those whose diabetes was first ascertained at the earlier time point $(P=0 \cdot 08)$. This pattern runs counter to what would be expected if early disease led to a reduction in coffee intake.

\section{Discussion}

In the current prospective cohort study of Puerto Rican men, we found significant associations of coffee intake with incident diabetes. In comparison to those drinking 1-2 servings/d, both abstaining from coffee and drinking 3 or more servings daily were inversely associated with incident diabetes. Among coffee drinkers, odds ratios declined across increasing categories of coffee intake; this trend was statistically significant $(P=0 \cdot 02)$.

The association of diabetes with coffee intake seen in the present study among coffee drinkers only is consistent with results of other cohort and cross-sectional studies on this topic, which suggest a protective association of coffee with risk of type 2 diabetes characterized by a monotonic dose-response extending through the full range of coffee intake $^{(5-17)}$. The moderate reduction in risk from lowest to highest intake categories is comparable to those seen in other prospective studies ${ }^{(26)}$, in spite of differences between our study and others in methods (disease ascertainment and exposure measurement) and populations (ethnicity, coffee preparation and serving size). While adjusted mean differences in coffee intake by diabetes outcome are small, odds ratios across the range of intake suggest that coffee intake can have a modest but significant impact on risk of disease.

Our finding of an inverse association with diabetes when coffee abstainers are compared with those having low coffee intake is in contrast to other studies, which have not reported the non-linear pattern of associations shown here. In most prospective studies, participants reporting no coffee intake appear to be at higher risk of diabetes compared with coffee drinkers ${ }^{(6,8,11,12)}$; in 
remaining studies, abstainers are considered together with participants having low coffee intake and so differences in risk cannot be discerned ${ }^{(5,7,13)}$. In our study sample, only 352 , or $7 \cdot 5 \%$, reported no coffee intake.

Abstainers from alcohol have often been found to differ from others in their health habits and lifestyle choices $^{(27,28)}$, and the same may be true for coffee in some populations. We hypothesized that abstaining from coffee might have been considered a 'prudent' health-conscious lifestyle choice in this population and so tested for associations with selected factors. In our study sample, coffee abstainers were more likely than coffee drinkers to live in urban areas $(P<0 \cdot 001)$, were less likely to have no formal education $(P<0 \cdot 01)$, were less likely to be current smokers $(P<0 \cdot 001)$, and were associated with two out of three considered markers of a prudent diet. In comparison to coffee drinkers, abstainers had higher intake of fruits and fruit juices $(P<0 \cdot 001)$ and lower intake of saturated fats $(P=0 \cdot 01)$; no significant association was seen for vegetable intake. However, when these dietary measures were added to logistic models of incident diabetes, it did not significantly attenuate the observed inverse association of abstaining from coffee with diabetes.

The present study has a number of important strengths, primary among them being the thorough assessment of diabetes status both at baseline and during at least one subsequent study visit. In our study diabetes was assessed using multiple methods, which included both fasting glucose tests and self-reports of physician-diagnosed diabetes and diabetes medication use; thus we avoid a major pitfall of many epidemiological studies of diabetes, namely under-diagnosis of this disease, which is often asymptomatic in its earlier stages. Thus the study benefits from both effective exclusion of all prevalent cases at baseline and relatively complete ascertainment of incident diabetes. In addition, major potential confounders were assessed, including BMI, physical activity and family history of diabetes.

In sensitivity analyses we considered a number of study limitations, including the nature of the coffee intake measure and the potential biases that could result from exclusion of the many potentially eligible study participants who failed to fast prior to their fasting glucose test and relatively short follow-up times. We do not feel that our findings can be explained as a result of these limitations. We submit that results of our study support the hypothesis that coffee intake can be protective with respect to diabetes risk, but also point to questions about the shape of the dose-response curve and to the fact that coffee drinking is a behaviour that may be associated with dietary patterns or with other lifestyle and health behaviours that may also influence diabetes risk.

While a coherent body of epidemiological evidence supports the hypothesis that coffee drinking can be protective against risk of type 2 diabetes, there are still many unanswered questions. Type 2 diabetes is a disease with complex aetiology, and coffee could reduce risk by acting on one or on multiple pathogenic mechanisms. Coffee contains substances including caffeine, chlorogenic acids, $\mathrm{Mg}$ and lignans that could reduce diabetes risk through beneficial effects on energy balance ${ }^{(14)}$, insulin sensitivity ${ }^{(29)}$, intestinal glucose absorption and $\beta$-cell survival ${ }^{(30)}$, liver function $^{(31)}$ and/or systemic inflammation ${ }^{(29,30)}$. Longterm intervention trials should be conducted in order to demonstrate that the association seen in observational studies represents a causal effect, to assess chemopreventive efficacy and potential adverse effects associated with varying doses and/or patterns of intake, and to explore biological mechanisms that may underlie the observed association between coffee intake and diabetes risk.

\section{Acknowledgements}

Funding: The work was partially supported by grants from the Department of Defense (DAMD17-02-1-0252) and the National Institutes of Health (1P20CA96256-01A1, 1R03 CA103475-01).

Conflicts of interest: The authors have no financial conflicts of interest to report.

Roles of study investigators: study concept and design M.R.G.-P. and C.J.C.; acquisition of data - M.R.G.-P. and C.J.C.; analysis and interpretation of data - B.J.F., C.J.C. and E.S.; drafting of the manuscript - B.J.F. and E.S.; critical revision of the manuscript for important intellectual content - C.J.C., E.S. and M.R.G.-P.; administrative, technical and material support - M.R.G.-P. and C.J.C.

\section{References}

1. Wild S, Roglic G, Green A, Sicree R \& King H (2004) Global prevalence of diabetes: estimates for the year 2000 and projections for 2030. Diabetes Care 27, 1047-1053.

2. Kenny SJ, Aubert RE \& Geiss LS (1995) Prevalence and incidence of non-insulin dependent diabetes. In Diabetes in America, 2nd ed., pp. 47-69 [NDD Group, editor]. Bethesda, MD: National Institute of Diabetes and Digestive and Kidney Diseases.

3. Chowdhury PP, Balluz L, Murphy W et al.; Centers for Disease Control and Prevention (CDC) (2007) Surveillance of certain health behaviors among states and selected local areas - United States, 2005. MMWR Surveill Summ 56, issue $4,1-160$.

4. Minino AM, Arias E, Kochanek KD, Murphy SL \& Smith BL (2002) Deaths: final data for 2000. Natl Vital Stat Rep 50, issue $15,1-119$.

5. van Dam RM \& Feskens EJ (2002) Coffee consumption and risk of type 2 diabetes mellitus. Lancet 360, 1477-1478.

6. Salazar-Martinez E, Willett WC, Ascherio A, Manson JE, Leitzmann MF, Stampfer MJ \& Hu FB (2004) Coffee consumption and risk for type 2 diabetes mellitus. Ann Intern Med 140, 1-8.

7. Carlsson S, Hammar N, Grill V \& Kaprio J (2004) Coffee consumption and risk of type 2 diabetes in Finnish twins. Int J Epidemiol 33, 616-617.

8. van Dam RM, Dekker JM, Nijpels G, Stehouwer CD, Bouter LM \& Heine RJ (2004) Coffee consumption and incidence of impaired fasting glucose, impaired glucose tolerance, 
and type 2 diabetes: the Hoorn Study. Diabetologia $\mathbf{4 7}$, 2152-2159.

9. Rosengren A, Dotevall A, Wilhelmsen L, Thelle D \& Johansson S (2004) Coffee and incidence of diabetes in Swedish women: a prospective 18-year follow-up study. J Intern Med 255, 89-95.

10. Tuomilehto J, Hu G, Bidel S, Lindstrom J \& Jousilahti P (2004) Coffee consumption and risk of type 2 diabetes mellitus among middle-aged Finnish men and women. JAMA 291, 1213-1219.

11. van Dam RM, Willett WC, Manson JE \& Hu FB (2006) Coffee, caffeine, and risk of type 2 diabetes: a prospective cohort study in younger and middle-aged US women. Diabetes Care 29, 398-403.

12. Pereira MA, Parker ED \& Folsom AR (2006) Coffee consumption and risk of type 2 diabetes mellitus: an 11-year prospective study of 28812 postmenopausal women. Arch Intern Med 166, 1311-1316.

13. Hu G, Jousilahti P, Peltonen M, Bidel S \& Tuomilehto J (2006) Joint association of coffee consumption and other factors to the risk of type 2 diabetes: a prospective study in Finland. Int J Obes (Lond) 30, 1742-1749.

14. Greenberg JA, Axen KV, Schnoll R \& Boozer CN (2005) Coffee, tea and diabetes: the role of weight loss and caffeine. Int J Obes (Lond) 29, 1121-1129.

15. Paynter NP, Yeh HC, Voutilainen S, Schmidt MI, Heiss G, Folsom AR, Brancati FL \& Kao WH (2006) Coffee and sweetened beverage consumption and the risk of type 2 diabetes mellitus: the Atherosclerosis Risk in Communities Study. Am J Epidemiol 164, 1075-1084.

16. Reunanen A, Heliovaara M \& Aho K (2003) Coffee consumption and risk of type 2 diabetes mellitus. Lancet 361, 702-703.

17. Saremi A, Tulloch-Reid M \& Knowler WC (2003) Coffee consumption and the incidence of type 2 diabetes. Diabetes Care 26, 2211-2212.

18. Fernandez NA, Burgos JC, Plough IC, Roberts LJ \& Asenjo CF (1996) Nutritional status of people in isolated areas of Puerto Rico. Survey of Barrio Naranjo, Moca, Puerto Rico. Am J Clin Nutr 19, 269-284.

19. Tucker KL, Bianchi LA, Maras J \& Bermudez OI (1998) Adaptation of a food frequency questionnaire to assess diets of Puerto Rican and non-Hispanic adults. Am J Epidemiol 148, 507-518.

20. World Health Organization (1999) Definition, Diagnosis and Classification of Diabetes Mellitus and its Complications: Report of a WHO Consultation. Part 1: Diagnosis and Classification of Diabetes Mellitus. Geneva: WHO.

21. Watt B \& Merrill A (1963) Agriculture Handbook No 8: Composition of Foods - Raw, Processed, Prepared. Washington, DC: Consumer and Food Economics Research Division, US Department of Agriculture.

22. Garcia-Palmieri MR, Costas R Jr, Cruz-Vidal M, Sorlie PD \& Havlik RJ (1982) Increased physical activity: a protective factor against heart attacks in Puerto Rico. Am J Cardiol 50, 749-755.

23. Karvetti RL \& Knuts LR (1985) Validity of the 24-hour dietary recall. J Am Diet Assoc 85, 1437-1442.

24. Donato F, Boffetta P, Fazioli R, Gelatti U \& Porru S (1998) Reliability of data on smoking habit and coffee drinking collected by personal interview in a hospital-based casecontrol study. Eur J Epidemiol 14, 259-267.

25. Schreiber GB, Maffeo CE, Robins M, Masters MN \& Bond AP (1988) Measurement of coffee and caffeine intake: implications for epidemiologic research. Prev Med 17, 280-294.

26. van Dam RM \& Hu FB (2005) Coffee consumption and risk of type 2 diabetes: a systematic review. JAMA 294, 97-104.

27. Ma J \& Hampl J (2000) Clustering of lifestyle behaviors: the relationship between cigarette smoking, alcohol consumption, and dietary intake. Am J Health Promot 15, 107-117.

28. Mukamal KJ, Ding EL \& Djousse L (2006) Alcohol consumption, physical activity, and chronic disease risk factors: a population-based cross-sectional survey. $B M C$ Public Health 6, 118.

29. McCarty MF (2005) Magnesium may mediate the favorable impact of whole grains on insulin sensitivity by acting as a mild calcium antagonist. Med Hypotheses 64, 619-627.

30. McCarty MF (2005) A chlorogenic acid-induced increase in GLP-1 production may mediate the impact of heavy coffee consumption on diabetes risk. Med Hypotheses $\mathbf{6 4}$, 848-853.

31. La Vecchia C (2005) Coffee, liver enzymes, cirrhosis and liver cancer. J Hepatol 42, 444-446. 